\title{
A Case of Hashimoto's Thyroiditis Induced Coagulopathy
}

\section{Lewis AS, Benson G, Courtney CH}

\section{Belfast Health and Social Care Trust}

\section{HISTORY}

A 26yr old man presented to haematology with a short history of easy bruising. There was no history of spontaneous bleeding. Past medical history was unremarkable other than childhood asthma for which he was on inhalers. Family history was non-contributory. On examination there was significant lower limb bruising. Investigation of coagulation indicated the following:

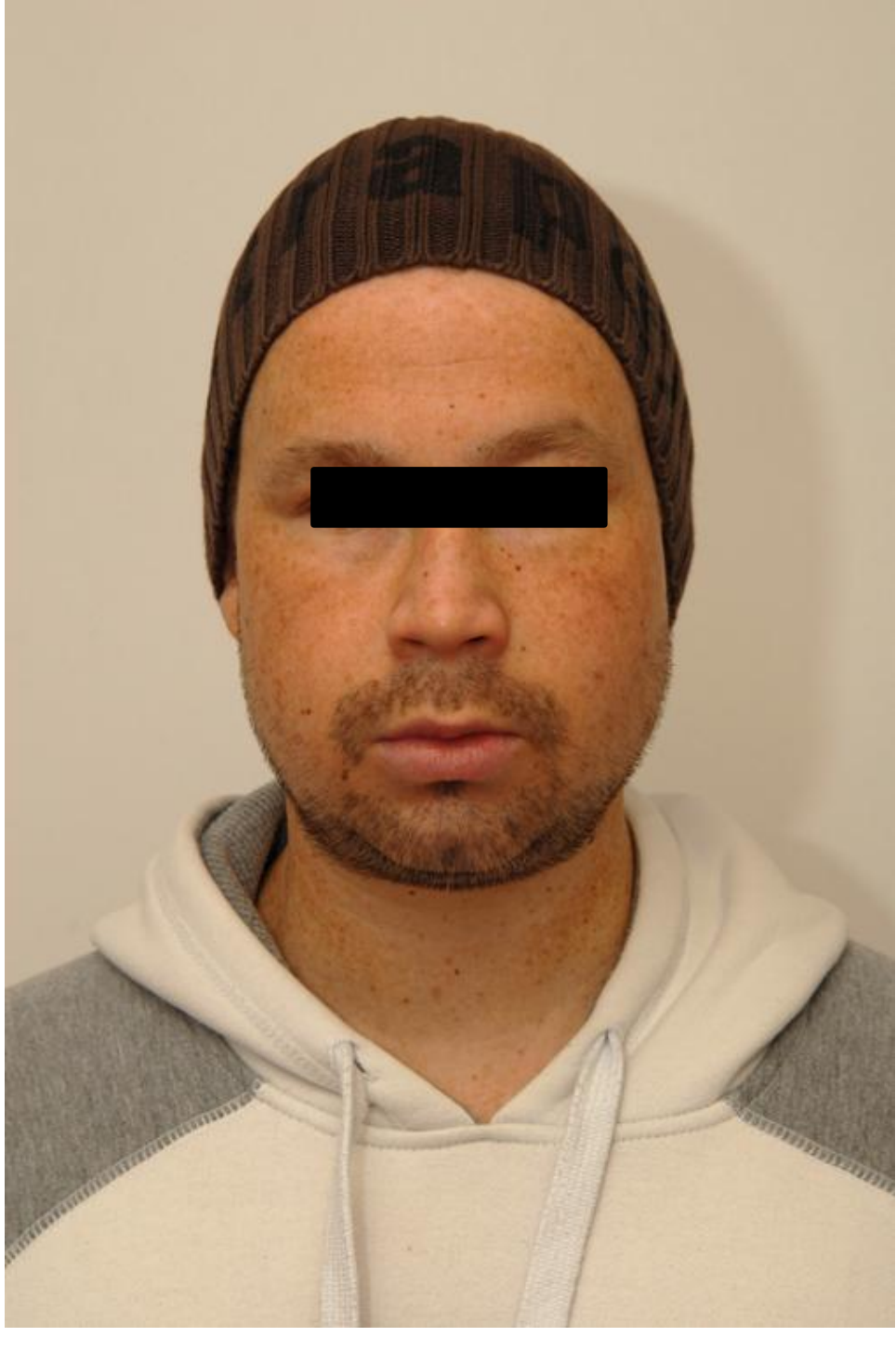

Fig 1. Photograph indicating typical hypothyroid facies

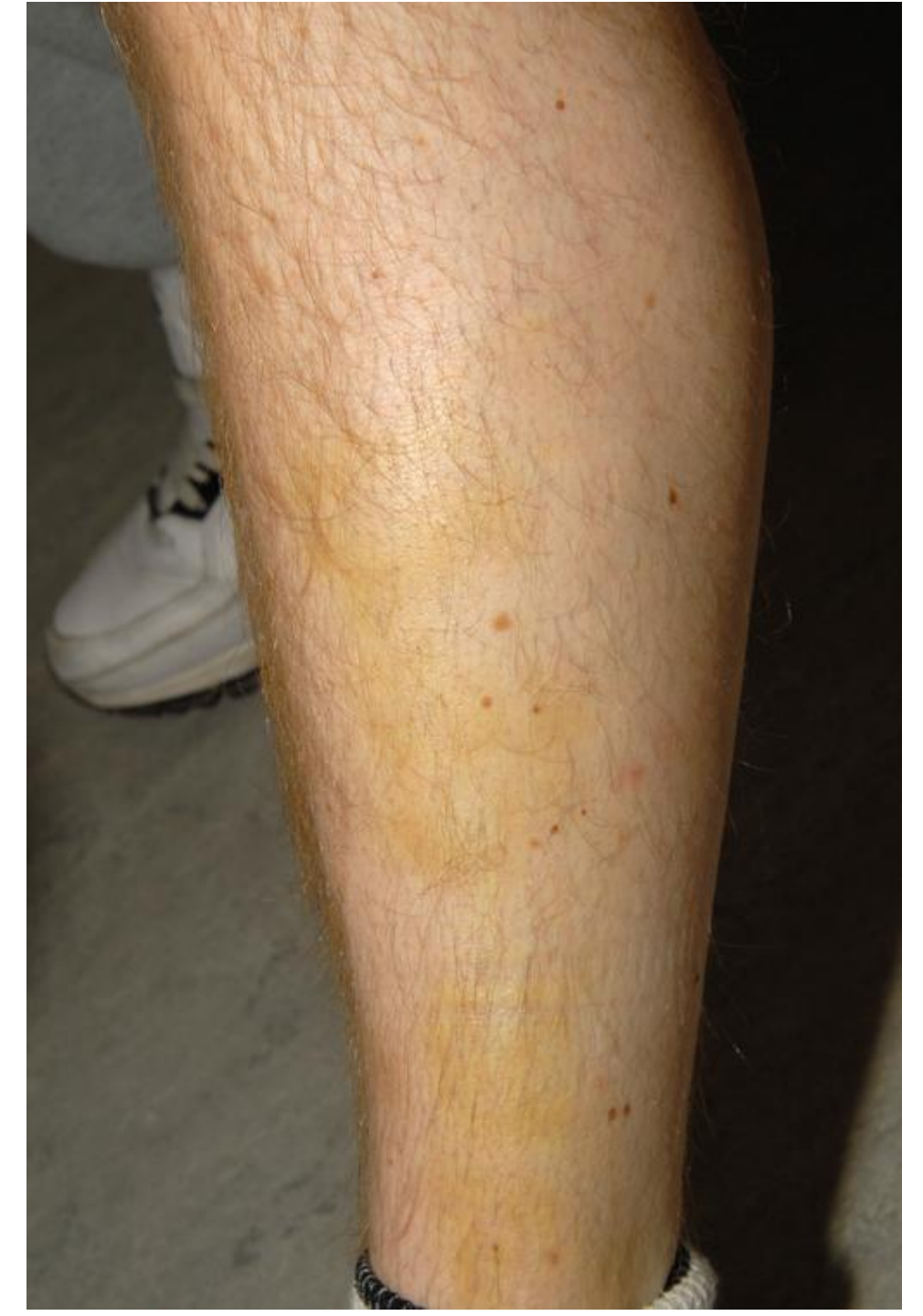

Fig 2. Photograph demonstrating bruising in lower limbs at presentation

\section{INVESTIGATIONS}

\begin{tabular}{|l|c|c|}
\hline & Result & Normal Range \\
\hline Platelets & 238 & $150-450$ \\
\hline Prothrombin time & 12.0 & $12-17$ secs \\
\hline APTT & 41.0 & $24-38$ secs \\
\hline Chromogenic Factor VIII & 0.46 & $0.6-1.3 \mathrm{U} / \mathrm{dl}$ \\
\hline Factor VIII clotting assay & 0.4 & $0.6-1.3 \mathrm{U} / \mathrm{ml}$ \\
\hline von Willebrand Factor antigen & 0.31 & $0.7-2.0 \mathrm{U} / \mathrm{ml}$ \\
\hline von Willebrand Factor activity & 0.39 & $0.7-2.0 \mathrm{U} / \mathrm{ml}$ \\
\hline Factor IX assay & 0.63 & $0.6-1.3 \mathrm{U} / \mathrm{ml}$ \\
\hline Factor XI assay & 0.60 & $0.6-1.3 \mathrm{U} / \mathrm{ml}$ \\
\hline
\end{tabular}

Elevation in APTT indicated an intrinsic pathway abnormality and further deficiencies in factor VIII and von Willebrand Factor antigen and activity confirmed a diagnosis of Acquired von Willebrand's disease The causes of acquired von Willebrand's disease are listed below

\section{ACQUIRED VON WILLEBRAND’S DISEASE}

Malignant disease
MGUS and multiple myeloma
Non Hodgkin lymphoma
Chronic lymphocytic leukaemia
Polycythaemia vera; Chronic myeloid leukaemia; Essential thrombocythaemia

Other disorders
SLE
Hypothyroidism
Gl angiodysplasia
Uraemia

von Willebrand disease continued...

Drugs
Sodium valproate
Ciprofloxacin
Griseofulvin

On further questioning he reported cold intolerance, dry skin and lethargy and family history revealed an aunt with hypothyroidism. Thyroid function tests were sent:

\begin{tabular}{|l|c|c|} 
& Result & Normal Range \\
\hline Free $\mathrm{T}_{4}$ & $<5.5$ & $9.0-19.0 \mathrm{pmol} / \mathrm{I}$ \\
\hline TSH & 711.1 & $04 .-4.5 \mathrm{mU} / \mathrm{l}$ \\
\hline Anti TPO Abs & 3000 & $0-135 \mathrm{U} / \mathrm{ml}$ \\
\hline
\end{tabular}

He was diagnosed with Hashimoto's thyroiditis, commenced on thyroxine replacement (100mcg daily ) and coagulation normalised as thyroid function improved

\begin{tabular}{|l|c|c|c|c|c|c|c|} 
Date & $\begin{array}{c}\text { Free T4 } \\
\text { ( } \mathbf{p m o l} / \mathbf{L})\end{array}$ & $\begin{array}{c}\text { TSH } \\
(\mathbf{m U / L})\end{array}$ & $\begin{array}{c}\text { Thyroxine } \\
\text { dose (mcg) }\end{array}$ & $\begin{array}{c}\text { APTT } \\
\mathbf{( 2 4 - 3 8 ~ s e c s )}\end{array}$ & $\begin{array}{c}\text { VIII Clotting } \\
\text { assay } \\
\mathbf{( 0 . 6 - 1 . 3} \\
\mathbf{U} / \mathbf{m l})\end{array}$ & $\begin{array}{c}\text { vWF } \\
\text { antigen } \\
\mathbf{( 0 . 7 - 2 . 0} \\
\mathbf{U} / \mathbf{m l})\end{array}$ & $\begin{array}{c}\text { vWF } \\
\text { activity } \\
\mathbf{( 0 . 5 8 - 1 . 9 6} \\
\mathbf{U} / \mathbf{m l})\end{array}$ \\
\hline Aug 10 & $<5.5$ & 711.1 & & 41.0 & 0.40 & 0.31 & 0.39 \\
\hline Nov 10 & 13.2 & 11.4 & 100 & 36.3 & 0.71 & 0.58 & 0.78 \\
\hline Apr 11 & 14.1 & 57.1 & 100 & 30.3 & & & \\
\hline Jan 12 & 18.0 & 40.2 & 125 & & & & \\
\hline Jan 13 & 20.0 & 2.24 & 150 & 34.0 & 0.67 & 0.65 & 0.61
\end{tabular}

\section{DISCUSSION}

Coagulation disorders can occur in up to $3 \%$ of patients with thyroid disease ranging from subclinical findings to haemorrhage or thromboembolism. Coagulation disturbance in hypothyroidism is usually associated with varying severity of disorders of haemostasis. Von Willebrand's disease is the most common disorder occurring and is characterised by easy bruising, epistaxis or mucosal bleeding. It is confirmed on laboratory finding of increased APTT with reduced factor VIII and vWF.

The pathogenesis is unclear but has been attributed to a reduction in VWF protein synthesis in the absence of adequate levels of thyroxine and reduced adrenergic stimulus which stimulates vWF synthesis.

It responds to treatment with desmopressin with normal half life times for factor VIII and VWF and disappears completely with thyroxine replacement.

\section{CONCLUSION}

This case demonstrates an interesting endocrine cause of coagulopathy which is simply and completely reversible with thyroxine replacement. 